\title{
Distancia de rescate, de Samanta Schweblin
}

\section{Luis Alvarenga Universidad Centroamericana "José Simeón Cañas", UCA}

Aunque haya una distancia de por medio, nunca es posible salir ileso de una pesadilla. Esto es lo que vemos en el modo en que se narra esta historia, la historia de las víctimas de una fuente de agua envenenada en una zona rural. Esta historia se titula Distancia de rescate -ya veremos qué significa este término-y su autora es Samanta Schweblin (Buenos Aires, 1978). Es una de las narradoras latinoamericanas contemporáneas más interesantes, amén de su reconocimiento internacional -expresado, por ejemplo, en el hecho de que la novela que nos ocupa fue una de las finalistas del Man Booker's Prize en 2017. Este es el premio que en el Reino Unido se otorga a una obra traducido al inglés. Kentukis, la segunda novela de esta autora nacida en Buenos Aires en 1978, fue finalista en 2020.

Podríamos arriesgarnos a definir Distancia de rescate como el relato de la progresión del desastre, como la inminencia de lo terrible. Su ritmo narrativo se parece a la mecha encendida de un explosivo. Amanda, una mujer que llega con su esposo y su hija Nina, a quedarse en una zona rural, es testigo de la tragedia de su amiga Amanda, cuyo hijo, David, ha bebido las aguas de un riachuelo envenenado. Amanda está reconstruyendo los hechos en sus últimas horas de vida, interrogada por la voz de David.

\section{La distancia de rescate}

La expresión que da nombre al relato que nos ocupa es "distancia de rescate”. Aparece por vez primera cuando Amanda recuerda una conversación en la que Carla se reprocha por el envenenamiento de David:
"Me pregunto si podría ocurrirme lo mismo que a Carla. Yo siempre pienso en el peor de los casos. Ahora mismo estoy calculando cuánto tardaría en salir corriendo del coche y llegar hasta Nina si ella corriera de pronto hasta la pileta y se tirara. 
Lo Llamo 'distancia de rescate', así llamo a esa distancia variable que me separa de mi hija y me paso la mitad del día calculándola, aunque siempre arriesgo más de lo que debería" (Schweblin, 2018, p. 22). Lo variable de dicha distancia es lo que hace que se convierta en una carga, en una espada de Damocles que no se sabe si caerá o no. La culpabilidad envenena también a quienes cargan con la distancia de rescate.
Hay, sin embargo, un sentido tácito de la palabra distancia a lo largo del relato. El diálogo en el que se va desgranando la historia, en el que Amanda reconstruye la historia, hecho en la forma de un interrogatorio por parte de David, es posible mediante una distancia que se tiende entre la narradora y lo narrado, incluyendo acá el proceso en el que se declaran, poco a poco, los indicios de la muerte. Volveremos más adelante sobre este punto.

\section{Lo sobrenatural y lo monstruoso}

Desde una perspectiva panorámica, por decirlo de algún modo, la metáfora suprema del relato es el doble envenenamiento la tarde fatídica en que arranca la narración. El agua del riachuelo está envenenada. Por ella, muere el semental de alquiler que usaba Omar, el marido de Carla, para que fecundara sus yeguas y vender las crías, atractivas por ser descendientes de animales de pura sangre (Schweblin, 2018, p. 21). Por ella, se envenena también David, quien es un niño pequeño. El doble envenenamiento es muy elocuente en lo que toca a las relaciones familiares. La presencia del padre, Omar, es fantasmal, como lo es también la del marido de Carla, cuyo nombre desconocemos. Omar parece apenas en momentos como éste, en el que sus intereses, económicos en este caso, se ven afectados:
"El padrillo tenía los párpados tan hinchados que no se le veían los ojos. Tenía los labios, los agujeros de la nariz, toda la boca tan hinchada que parecía otro animal, una monstruosidad. Apenas tenía fuerzas para quejarse y Omar dijo que el corazón le latía como una locomotora. Mandó a llamar urgente al veterinario, vinieron algunos vecinos, todo el mundo preocupado corriendo de acá para allá (...)" (Schweblin, 2018, p. 21).

Esta angustia de Omar por el caballo, se contrasta con la reacción de Amanda, en ese mismo párrafo:

“(...) pero yo volví desesperada a la casa, saqué a David que todavía dormía en su cuna y me encerré en el cuarto, en la cama con él en brazos para rezar. Rezar como una loca, rezar como nunca había rezado en mi vida. Pensarás por qué no corrí 
a la guardia en lugar de encerrarme en la habitación, pero a veces no hay tiempo para confirmar el desastre. Lo que sea que hubiera tomado el caballo lo había tomado también mi David, y si el caballo se estaba muriendo no había chances para él" (Schweblin, 2018, p. 21).

Hemos hablado del agua envenenada del riachuelo. "El agua es vida", dice más de algún eslogan. El flujo de la vida está enrarecido por las obras humanas. Pero, por otra parte, son las obras humanas parte de lo que hace posible dicho flujo. Envenenar el flujo de la vida es una transgresión del orden natural de las cosas. Esta transgresión, de algún modo, debe castigarse. Ello se engarza con la noción de lo monstruoso, que abordaremos más adelante.

Con el episodio del doble envenenamiento, se desencadenan varios elementos. Estos tienen como origen la culpabilidad atribuida implícitamente a Carla:

-El recurso a lo divino y a la magia, para evitar el desenlace fatal. Esto tendrá un precio para los involucrados. Esto funda también la forma precisa en que se narra la historia.

-La emergencia de lo monstruoso, desde la consabida categoría de lo monstruoso como amenaza moral, pero también como el catalizador de las revelaciones.
La desesperación de Carla la lleva a buscar una solución que va más allá de este mundo: seguirá el consejo debe ir a visitar a "la mujer de la casa verde", quien no es bruja ni adivina. Su poder es "leer" la energía de la gente, con lo cual "puede saber si alguien está enfermo y en qué parte del cuerpo está esa energía negativa. Cura el dolor de cabeza, las náuseas, las úlceras de la piel y los vómitos con sangre. Si llegan a tiempo, detiene los abortos espontáneos", se afirma (Schweblin, 2018, p. 23). La mujer de la casa verde sería una encauzadora de las energías, un canal o medio (literalmente, una médium) para que estas energías puedan fluir mejor. El riachuelo y las energías vitales: metáforas de lo fluido de la vida.

La sesión con la mujer de la casa verde plantea una nueva situación, en la cual es posible frenar el avance de los efectos de la intoxicación, pero será necesario practicar lo que aquí se llama "una migración" (Schweblin, 2018, p. 26), esto es mudar "a tiempo el espíritu de David a otro cuerpo", con lo cual "parte de la intoxicación se iba con él" (Schweblin, 2018, p. 26). Desde esta lógica, al estar la intoxicación "dividida en dos cuerpos había chances de superarla. No era algo seguro, pero a veces funcionaba" (Schweblin, 2018, pp. 26-27). Había que correr el riesgo, razona Carla, pues "era la única manera que tenía de conservar a David. La mujer me acercó un té, 
dijo que beberlo despacio me calmaría, que me ayudaría a tomar mi decisión, pero yo me lo tomé en dos tragos. No podía ni siquiera ordenar lo que estaba escuchando. Mi cabeza era una maraña de culpa y terror y el cuerpo entero me temblaba" (Schweblin, 2018, p. 27).

Así, David recupera la vida, pero su alma está escindida. Escisión del alma: ¿no es este, acaso, el significado literal de la palabra esquizofrenia? David sigue siendo un niño, en el nivel objetivo del relato, pero aquella parte de su alma que, creemos, está dentro de la madre y que la interroga, es una voz adulta. Su frialdad, su insistencia en que su interlocutora narre con detallada precisión cosas como el instante en que empiezan a aparecer los gusanos en su cuerpo, esa cruel voz adulta, evoca de alguna forma a Regan McNeil, la niña protagonista de $E l$ exorcista, cuando oímos la ronca voz de uno de los demonios que la posee canalizarse por su boca infantil. No es esta, sin embargo, una novela sobre posesión demoníaca, sino sobre el envenenamiento del alma escindida de los protagonistas. La culpabilidad divide el alma de Carla y Amanda. Tienen miedo de verse como las asesinas -por omisión, por tardanza en surcar la distancia de rescate- de sus descendientes.

Culpabilidad y esquizofrenia: esa es condición de posibilidad de narrar la propia muerte y de reconstruir el hecho fundacional de la culpa ante el fantasma-voz interior del hijo.

Con la “migración”, David adquiere otra característica, aparte de la división de su alma: es un monstruo. En el blog de Alberto Bustos encontramos una explicación interesante sobre la etimología del vocablo monstruo, que puede ser útil para continuar nuestro camino. Bustos afirma que:

La palabra monstruo viene del latín monstrum a través de una forma vulgar monstruum. Esta, a su vez, se deriva del verbo monere, que significa 'advertir'. Un monstruo era un aviso, una advertencia que enviaban al mundo las fuerzas sobrenaturales. Originariamente, la palabra se utilizaba para referirse a un portento de la naturaleza, pero muy especialmente a un ser deforme. En la Antigüedad, cuando nacía un niño o un animal con algún tipo de malformación, se creía que eso era un aviso: los dioses nos enviaban estas criaturas como señal de que iba a suceder algo terrible. Esta creencia se mantuvo bien viva durante la Edad Media y todavía en el inicio de la Edad Moderna. (Bustos, A. 18 de diciembre de 2014).

Luego Bustos añade esta cita del Tesoro de la lengua castellana, de Sebastián Cobarrubias, que nos viene bien: 
MONSTRO, es cualquier parto contra la regla y orden natural, como nacer el hombre con dos cabeças, quatro brazos, y quatro piernas; como aconteció en el condado de Urgel, en un lugar dicho Cerbera, el año 1343, que nació un niño con dos cabeças, y quatro pies. Los padres y los demás que estavan presentes a su nacimiento, pensando supersticiosamente pronosticar algún gran mal, y que con su muerte se evitaría le enterraron vivo. Sus padres fueron castigados como parricidas, y los demás con ellos. (Bustos, A. 18 de diciembre de 2014).

Lo monstruoso aparece desde el temor que expresa Amanda sobre su pequeña hija: "Estaba convencida de que le faltaba un dedo" (Schweblin, 2018, p. 16), hasta la procesión de niños envenenados en un sanatorio (Schweblin, 2018, pp. 107-108):

"Son chicos extraños. Son, no sé, arde mucho. Chicos con deformaciones. No tiene pestañas, ni cejas, la piel es colorada, muy colorada, y escamosa también. Solo unos pocos son como vos.

\section{¿Cómo soy yo, Amanda?}

No sé, David, ¿más normal? Ya cruza el último" (Schweblin, 2018, p. 108).

Un aviso, una amonestación de los dioses. La monstruosidad de
David, el dedo falsamente perdido de Nina, la hija de Amanda, es el castigo divino en virtud del cual la muerte avanza por el cuerpo de la narradora. Lo monstruoso también es lo que abre la posibilidad de una revelación. Como en la pieza dramática Los reyes (Cortázar, 2001), en la que Julio Cortázar nos deja ver que el Minotauro no es el monstruo, sino Teseo, el héroe. La monstruosidad del héroe se expresa en su abominable normalidad: su ambición, su deseo de gloria, que se contrastan con la inocencia de Minotauro.

La monstruosidad sería, pues, la advertencia divina de que el orden natural de la realidad ha sido transgredido. Esta ofensa es punible. El único castigo válido es la muerte. Hay anuncios de ello: desde la ya mencionada mutilación imaginaria del dedo y la procesión de los niños anormales, pasando por el encuentro con una niña que tiene una pierna más corta que la otra (Schweblin, 2018, p. 43), hasta aquel pasaje en el que se oye a Nina decir: "Soy David" (Schweblin, 2018, p. 56 ), y, una de las cosas más siniestras: el entierro del pato y de otros animales por parte de David (Schweblin, 2018, p. 71), animales que mueren sin que éste los toque, mientras Nina canta frenéticamente "nos encanta, nos encanta, nos encanta” (Schweblin, 2018, p. 73).

Amanda y Carla intentan huir de la maldición, pero están atadas. No solo por los efectos progresivos 
del envenenamiento, en el caso de Carla, sino por la "distancia de rescate", que, como ésta recuerda, le viene transmitida por su madre. El único personaje que tiene éxito en la huida es el esposo de Carla, quien logra tomar su automóvil. Al igual que Omar es el hombre de éxito (éxito igual al vocablo inglés exit: el éxito como evasión), hasta que la maldición -que de manera tácita se le achaca a Carla, por haber sido incapaz de recorrer oportunamente la distancia de rescate y evitar el envenenamiento de David- se lleva consigo al padrillo. Por tanto, y ante la imposibilidad de recuperar su fuente de ingresos y el problema de indemnizar al dueño del caballo, huirá del pueblo: "Mi marido se sube al coche furioso, mientras las dos figuras se alejan, regresan a la casa, distantes, primero entra una, después la otra, y la puerta se cierra desde dentro" Schweblin, 2018, p. 124).

Poco después, quedará atrapado en un atasco de tráfico. Su ausencia de la tragedia familiar, que se contrasta ostensiblemente con su remarcada presencia en la pérdida del padrillo -su tragedia personal- es también digna de castigo. Este castigo es la ceguera: la falta de empatía que le impide darse cuenta de que no puede esquivar la condena colectiva. Hemos atestiguado esa ceguera a lo largo de la novela. La ceguera se ve acompañada de la invisibilidad: La marcada ausencia de la figura del padre durante buena parte del relato.
La ceguera se hace mayor a medida que abandona el lugar maldito:

"No se detiene en el pueblo. No mira hacia atrás. No ve los campos de soja, los riachuelos entretejiendo las tierras secas, los kilómetros de campo abierto sin ganado, las villas y las fábricas, llegando a la ciudad. No repara en que el viaje de vuelta se ha ido haciendo más y más lento. Que hay demasiados coches, coches y más coches cubriendo cada nervadura de asfalto. Y que el tránsito está estancado, paralizado desde hace horas, humeando efervescente. No ve lo importante: el hilo finalmente suelto, como una mecha encendida en algún lugar; la plaga inmóvil a punto de irritarse" Schweblin, 2018, p. 124).

La "plaga inmóvil" es la latencia del mal, que tarde o temprano alcanzará al hombre que huye hacia la ciudad, es decir, hacia la civilización, a la certeza del lugar donde no hay riachuelos mortíferos. Como en la tragedia griega, el destino es insoslayable. La transgresión de la cual los monstruos son su evidencia, tendrá que pagarse.

La obra de Schweblin cobra, sin proponérselo, vigencia en este contexto de pandemia. La explícita inminencia de la muerte, su origen -marcado por la culpa, real o atribuida, a una zona geográfica, a un país, a unos individuos- es como el veneno que se esparce en el conjunto 
de relaciones humanas. Como en la marca que deja el hecho de no haber ficción antes comentada, tendemos a cumplido la distancia de rescate de refugiarnos, tanto en los repartos de las vidas de quienes amamos se culpabilidad, como en el recurso de extiende sobre nuestras existencias. lo sobrenatural. Y si hay una falla, la

\section{Referencias bibliográficas}

- Bustos, A. (18 de diciembre de 2014). Etimología de 'monstruo'. Recuperado de: https://blog.lengua-e.com/2014/etimologia-demonstruo/\#: :text=La\%20palabra\%20monstruo\%20viene\%20 del,\%2C\%20que\%20significa\%20'advertir'.

- Cortázar, J. (2001). Los reyes. Madrid: Alfaguara.

- Schweblin, S. (2018). Distancia de rescate. Barcelona: Random House. 